Original Contribution

\title{
PREDICTORS OF EMOTIONAL ILLNESS PERCEPTION IN PATIENTS WITH CHRONIC DISEASES
}

\author{
K. Mineva ${ }^{1^{*}}$, K. Peeva ${ }^{2}$ \\ ${ }^{1}$ Department of Medical Psychology and Foreign Languages, Medical Faculty, Trakia University, \\ Stara Zagora, Bulgaria \\ ${ }^{2}$ Department of Social Medicine and Health Management, Medical Faculty, Trakia University, \\ Stara Zagora, Bulgaria
}

\begin{abstract}
Illness perception manages illness behavior. Emotional illness perception refers to psychological distress of patients. 237 patients with rheumatic arthritis, ankylosing spondylitis, hypertension and diabetes mellitus type 2 have been studied. PURPOSE: The purpose of the study is to evaluate the influence of optimism, negative expectations, health locus of control and chronic disease self-efficacy on emotional illness perception. METHODS: Optimism and Negative expectancies Inventory, Multidimensional Health Locus of Control Scales, Brief Illness perception Questionnaire, Chronic Disease Self-efficacy Scales; Statistical methods: Kolmogorov-Smirnov test, Linear regression, ANOVA, Student's t-test, P value of less than 0.05 was regarded as significant. RESULTS: According to the data of the study, negative expectations and self-efficacy to manage symptoms and depression are significant predictors of distress. The negative expectations increase distress during an illness, whereas the self-efficacy reduces distress. Health locus of control and optimism are not significant factors of emotional distress level. High chronic disease self-efficacy is significantly associated with less distress. CONCLUSIONS: Perceived competence to manage physical symptoms and coping with psychological distress are equally important for adaptation to the disease. Negative expectations predict distress in chronic disease, optimism does not.
\end{abstract}

Key words: Illness perception, optimism, health locus of control, Self-efficacy

\section{INTRODUCTION}

Chronic disease is associated not only with physical changes in the body, but with concomitant emotional experience of the patient as well. According to the selfregulatory model (1) by meeting with disease patients are forming their own Illness perceptions, which consist of cognitive and emotional component. Cognitive perception refers to beliefs about symptoms, timeline, consequences, causes, consistency and perceived personal control and control of the treatment over the disease. Emotional perception refers to psychological distress. The self-regulatory model proves that mental health and illness behaviour are function of patients' illness perception. Based on their beliefs and emotions, patients are choosing coping strategies and implement behaviour to cope with the disease.

\footnotetext{
*Correspondence to: Kremena Mineva, Faculty of Medicine, Trakia University, 11 Armejska Str., Stara Zagora 6000, Bulgaria 35942/ 664 324, kremenamineva@abv.bg
}

Emotional perception reflects the personal sense of disease to the patient and determines his adaptation. Irrespective of type or severity of the disease, most of the patients experience sadness, anxiety, anger, depression. Sadness is associated with losses, which are associated with the body, capabilities, important role or social status. Increasing anxiety is due to uncertainty in the treatment and hospitalization or due to threats to autonomy, disability and loss of function, loss of body control and threat to life (2). Increasing of anger is associated with increasing of illness severity, worsened life perspectives, feelings of helplessness and injustice. Patients often feel guilty, lost selfesteem, have a sense of failure at life goals and pessimistic perception of the future (3).

Distress occurs in illness behaviour as inconsistency to treatment, substance abuse, aggression, searching for conflicts, complaints, irritability or excessive rigor. Depression occurs significantly more frequently in patients with chronic diseases in comparison to the general population. Between 
$9.3 \%$ and $23 \%$ of patients with one or more chronic disease have comorbid depression (4).

Perceiving stress is highly subjective. According the Theory of stress (5) the level of distress depends on the individual assessment of the influence of the event (positivenegative) and its controllability. Therefore it is important to establish personality factors that influence the emotional illness perception and predict distress.

In the scientific literature it is empirically proved that optimism as generalized positive expectation about the future reduces the level of perceiving stress. Optimists perceive situations as less stressful and more controllable than pessimists, which has beneficial effects on mental health. In contrast, negative expectations about the future are related to increased anxiety, sadness and despair (6). A number of studies emphasize that optimistic predicts lower anxiety and depression and higher satisfaction with life in patients with cardiovascular-disease (7), osteoarthritis (8) and cancer (9). Negative expectations are positively associated with depression after hospitalization of patients with ischemic heart disease and predict severe depression one year later (10). In cancer patients optimism predicts a high resistance to stress during treatment and reduces emotional distress, regardless of stage and development of the disease $(11,12)$.

According to the theory of Ajzen (2002) perceived control is determined by health locus of control and self-efficacy (13). The health locus of control refers to the beliefs about factors that control the disease. The internal health locus is associated with the belief that the disease is controlled by own behavior whereas external health locus of control- by factors such as chance or other people (14). Chronic disease Self -efficacy refers to perceived personal competence and skills for coping with the disease (15).

In the literature researches proves that internal health locus of control reduces distress. For example, Barez, M. et al. (2009) have found that internal health locus of control is an early predictor of psychological adaptation in patients with breast cancer and predicts distress of disease, measured one year later. The relationship between perceived control and psychological stress does not depend on disease severity (16). Livneh et al. (2004) have found that patients with high internal health locus of control have a lower degree of anxiety, depression and anger, higher quality and satisfaction with life, compared to patients with high external health locus of control and lower internal health locus of control (17). Rasheva, M. (2008) has found though that not only beliefs about personal control, but also beliefs about health locus of control about significant others are associated with lower depression and higher life satisfaction in patients with chronic disease (18).

According to Bandura (1997) high selfefficacy reduces perceived stress in stressful event (15). Beliefs about high personal abilities to cope with the disease improve well-being and lead to higher subjective assessment of health. Studies with rheumatoid arthritis and osteoarthritis patients has found that selfefficacy is significantly negatively associated with perceiving severity of symptoms, level of disability and psychological distress. Patients with higher self-efficacy evaluate their health as being better, perceive disease as one which is associated with less severe symptoms and declare less distress $(19,20)$.

The aim of this study is to determine the influence of optimism and negative expectations, health locus of control and chronic disease self-efficacy on emotional illness perception in patients with chronic diseases.

\section{MATERIALS AND METHODS \\ Persons examined}

237 patients with type 2 diabetes mellitus, hypertension, ankylosing spondylitis and rheumatoid arthritis of Bulgarian and Turkish ethnic origin, aged 25-84 years (Mean=53.96, $\mathrm{SD}=13.3$ ) have been examined. Criterion for inclusion in the study was a diagnosis, made by a physician, of one of these diseases. The respondents participated in the survey anonymously and voluntarily.

\section{Methods}

1. Optimism and Negative expectancies Inventory (21)

2. Multidimensional Health Locus of control Scales (form C) (14).

3. Self Efficacy Chronic Disease Scales (22)

4. Brief Illness perception Questionnaire (23)

Statistical methods used: Student's independent samples t-test; KolmogorovSmirnov test for normality; ANOVA, Linear regression analysis, $\mathrm{P}$ value of less than 0.05 was considered as significant.Cronbach's alpha coefficient of reliability for the items in questionnaire.All statistical analyses were 
MINEVA K., et al.

performed with IBM SPSS Statistics 19 software.

\section{RESULTS AND DISCUSSION}

One-way ANOVA established that there is not a statistically significant relationship between health locus of control and emotional illness perception. $(\mathrm{P}>0.05)$. Health beliefs about the factors that control the development of the disease do not influence emotional experience of the disease. We assume that this is due to the mechanism of influence of health beliefs on distress. Henselmans, I. et al. (2010) found that the internal health locus of control affects distress indirectly through two mediators assessment of lower severity of the disease and perception of higher coping abilities. Beliefs that the disease depends on one's own behavior are associated with positive illness cognitions and high self-efficacy. These mediators in turn influence the level of distress (24). We could assume that perceived personal control has direct effect on the cognitive illness perception and chronic disease self-efficacy, but it has not significant direct effect on the emotional illness perception. On the other hand, emotional distress depends on perceived severity of the symptoms, and the most depends on severity of pain. In our study in advance we found health locus of control is not significantly associated with pain sensitivity (25). We propose that health locus of control is not a significant factor on distress because of the lack of influence on perceived intensity of symptoms.

Analyses show that Chronic disease Selfefficacy (CDSE) is a significant factor for emotional illness perception $(\mathrm{P}<0.05)$. There are significant differences between group means of patients with high and low CDSE $(\mathrm{P}<0.05)$. Emotional distress was significantly higher in patients with low self-efficacy for exercising regularly, obtaining help from community, family, friends, managing disease in general, doing chores, maintaining social/recreational activities, managing symptoms and managing depression compared to patients with higher CDSE (Table 1). Other authors have also found that diabet patients with lower CDSE have significantly worse health status and higher levels of distress (26, 27). These results show that not the beliefs about the factors, that are controlling the disease, but the perceived competence of patients to cope with the disease significantly affects the level of distress.

Table 1. Comparison of emotional illness perception between patients with low and high level of Chronic Disease Self-efficacy (CDSE)

\begin{tabular}{|l|l|l|l|}
\hline Chronic Disease Self-efficacy & $\mathrm{t}$ - test, sig. & $\begin{array}{l}\text { Low CDSE } \\
\text { M (SD) }\end{array}$ & $\begin{array}{l}\text { high CDSE } \\
\text { M (SD) }\end{array}$ \\
\hline Exercise Regularly & $\mathrm{t}=2.69, \mathrm{P}=0.009$ & $7.24(2)$ & $5.65(1.8)$ \\
\hline $\begin{array}{l}\text { Obtain Help from Community, } \\
\text { Family, Friends }\end{array}$ & $\mathrm{t}=2.77, \mathrm{P}=0.007$ & $7.36(2.3)$ & $5(2.7)$ \\
\hline Manage Disease in General & $\mathrm{t}=3.726, \mathrm{P}=0.0001$ & $7.33(2.04)$ & $5.5(2.5)$ \\
\hline Do Chores & $\mathrm{t}=2.665, \mathrm{P}=0.01$ & $7.12(2.18)$ & $5.6(2.2)$ \\
\hline $\begin{array}{l}\text { Maintain Social/Recreational } \\
\text { Activities }\end{array}$ & $\mathrm{t}=2.62, \mathrm{P}=0.01$ & $7.22(2.32)$ & $5.8(2.5)$ \\
\hline Manage Symptoms & $\mathrm{t}=4.23, \mathrm{P}=0.0001$ & $7.6(2.08)$ & $5.4(1.7)$ \\
\hline Control/Manage Depression & $\mathrm{t}=4.672, \mathrm{P}=0.0001$ & $8(1.8)$ & $5.6(2)$ \\
\hline
\end{tabular}

We have found that there is not statistically significant relationship between optimism and emotional illness perception $(\mathrm{P}>0.05)$. The positive expectations for the future are not associated with the level of distress. However, there are significant differences in group means of emotional illness perception in patients with high and low negative expectations $(\mathrm{P}=0.002)$. Patients with high negative expectations have higher distress compared to patients with low negative expectations.
Linear regression analysis shows that negative expectations are a significant positive predictor of emotional illness perception $(\beta=0.52$, $\mathrm{P}=0.036)$ and chronic disease self-efficacy to manage symptoms $(\beta=-0.40, \mathrm{P}=0.027)$ and depression $(\beta=-0.31, P=0.018)$ are significant negative predictors in the model. The variables explain $18 \%$ of the variation in the level of distress. The model shows that increase in negative expectations leads to higher distress, whereas increase of the efficiency to manage symptoms and depression reduces distress. 
Optimism is not a significant predictor of distress. Other studies also have found that negative expectations for the future are a stronger and significant predictor of emotional illness perception, in comparison to optimism (28). Optimism could play a role of a buffer of stress, but influence of optimism on distress depends on the type of disease and its duration. For example, high optimism in patients with rheumatoid arthritis with longer duration of illness is associated with more severe symptoms and higher distress (29).

Negative expectations have the greatest impact on the level of distress as they are a major part of the cognitive component of anxiety. Anxiety is associated with differences in the valence (positive-negative) of the expecting events, mainly with anticipation of undifferentiated threat in the future. When expectations for the occurrence of a negative event are bigger than expected for the occurrence of a positive event, the social environment is perceived as stressful and the functioning as difficult. In addition to negative expectations about the future anxiety is also determined by perceived personal ability to deal with negative events. In case of disease symptoms of disease are perceived as a main threat to health. Therefore, the level of stress depends on the perceived severity of symptoms and their impact on well-being, as well as on the perceived control over them.

Symptoms can be somatic (e.g., increased blood pressure) and psychological (e.g. anxiety). In this sense, self-efficacy for symptom management and coping with depression may be accepted as ability to cope with somatic and psychological symptoms. According to the self-regulatory model physical symptoms and related emotions are processed in parallel and are interdependent. For example, in patients with chronic pain selfefficacy for control of symptoms significantly predicts the degree of depression (30). In turn, the higher distress increases the severity of the perceived symptoms. Patients with chronic diseases with higher anxiety report more intense pain. $(31,32)$. The relationship between physical symptoms and distress confirms that in the process of self-regulation of illness behavior equally important and necessary are skills to control the physical symptoms, as well as psychological symptoms.

Studies in patients with chronic diseases indicate that beliefs about higher control of symptoms are associated with better adaptation to the disease, compared to perceived control over disease. Patients with perceived higher control over daily symptoms experience less distress and have more positive cognition about the disease, in comparison to patients who are taking high personal control of the disease in general $(33,34)$.

On the other hand cognitive and emotional illness perception determines applied coping strategies, the results of which affect illness perception. According to Bandura (1977) selfefficacy regulates emotional state not only by affecting cognition and emotions, but also by the choice of coping. Perceived competence to implement effective health behavior increases motivation of patient to use this behavior (15). Also expectations for the future results are a main factor in the choice between two types of behavioral strategies: fight or refusal. People with high negative expectations perceive difficulties as permanent and uncontrollable, and the desired results as unattainable (6). In this regard, the negative expectations and low self-efficacy could lead to passive way of coping, which could lead to malfunction and increase distress. In the literature it is stated that the use of passive coping style of patients with chronic pain increases the intensity of the perceived pain (35). Considering the concept of self -regulatory model, we can assume that negative expectations and chronic disease selfefficacy not only affect the level of distress in chronic disease but are significant factors in the process of self-regulation of illness behavior.

\section{CONCLUSIONS}

Analysing the data in this study we can draw the following conclusions:

1. Distress in chronic disease depends on the perceived ability to cope with the symptoms and does not depend on beliefs about factors that control development of disease.

2. Perceived competence to manage physical symptoms and coping with psychological distress are equally important for adaptation to the disease.

3. Negative expectations are significant and stronger predictors of distress in chronic illness.

\section{REFERENCES}

1. Leventhal, H., Brissette, I., \& Leventhal, E. A., The common-sense model of self regulation of health and illness. In: L. D. Cameron, \& H. Leventhal (Eds.), The selfregulation of health and illness behaviour, London: Routledge, pp. 42-65, 2003.

2. Derogatis, L., Wise, T. Anxiety and depressive disorders in somatic illness patients. IK Lik, Sofia, ISBN: 954-607347-4, 2000. 
3. Falvo, Donna. R, Medical and Psychosocial Aspects of Chronic Illness and Disability 5Th Edition Jones and Bartlet Publishers, LLC. Chapter 2, p. 9-32, 2014.

4. Moussavi, Saba, Somnath Chatterji, Emese Verdes, Ajay Tandon, Vikram Patel, Bedirhan Ustun, Depression, chronic diseases, and decrements in health: results from the World Health Surveys, Lancet; 370: 851-58, 2007.

5. Lazarus, R. S. \& Folkman, S., Stress, appraisal and coping. New York: Springer Publishing Company, Inc, 1984.

6. Scheier, M. F., Carver, C. S., \& Bridges, M. W., Optimism, pessimism, and psychological well-being. In E. C. Chang (Ed.), Optimism and pessimism: Implications for theory, research, and practice, Washington, DC: American Psychological Association, pp. 189-216, 2001.

7. Karademash, E., Self-efficacy, social support and well-being The mediating role of optimism. Personality and Individual Differences, 40: 1281-1290, 2006.

8. Ferreira, V., \& Sherman, A., The relationship of optimism, pain and social support to well-being in older adults with osteoarthritis. Aging and Mental Health, 11, 89-98, 2007.

9. Applebaum A J., Stein E. M, Jennifer Lord-Bessen, Pessin H, Rosenfeld, B and Breitbart W., Optimism, Social Support, and Mental Health Outcomes in Patients with Advanced Cancer. Psychooncology; 23(3): 299-306, 2014.

10.Shnek, Z. M., Irvine, J., Stewart, D., \& Abbey, S., Psychological factors and depressive symptoms in ischemic heart disease. Health psychology, 20: 141-145, 2001.

11.Wimberly SR, Carver CS, Antoni MH, Effects of optimism, interpersonal relationships, and distress on psychosexual well-being among women with early stage breast cancer. Psychol Health., 23 (1):5772, 2008.doi:10.1080/14768320701204211.

12.Tomich PL, Helgeson VS., Cognitive adaptation theory and breast cancer recurrence: Are there limits? J Consult Clin Psychol., 74(5):980-987, 2006.

13.Ajzen, Icek, Perceived Behavioral Control, Self-Efficacy, Locus of Control, and the Theory of Planned Behavior. Journal of Applied Social Psychology, 32 (4): 665683, 2002.

14. Wallston, K., Stein, M., \& Smith, C., Form $\mathrm{C}$ of the MHLC scales: A conditionspecific measure of locus of control.
MINEVA K., et al.

Journal of Personality Assessment, 63(3): 534-553, 1994.

15.Bandura, A., Self-efficacy: Toward a unifying theory of behavioral change. Psychological Review, 84: 191-215, 1977.

16. Bárez $\quad \mathrm{M}$, Blasco $\mathrm{T}$, Fernández-Castro J, Viladrich C., Perceived control and psychological distress in women with breast cancer: a longitudinal study. J Behav Med.; 32(2):187-96, 2009. doi: 10.1007/s10865008-9180-5. Epub 2008 Sep 25.

17.Livneh, H., Lott, S. \& Antonak, R., Psychosocial Adaptation to Chronic Illness and Disability: A cluster analytic approach. Psychology, Health \& Medicine, 9 (4): 411430,2004.DOI:10.1080/1354850042000267 030.

18.Rasheva, M, Perceived control and adaptation to chronic disease. Psychological Research, ISSN 1311-4700, 1: 51-65, 2008

19. Mäkeläinen, P., K Vehviläinen-Julkunen, A Pietilä, A Survey of Rheumatoid Arthritis Patients Self-Efficacy. The Internet Journal of Advanced Nursing Practice, 9 (2), 2007.

20.Cross, M.J., L. M. March, H. M. Lapsley, E. Byrne and P. M. Brooks, Patient selfefficacy and health locus of control:relationships with health status and arthritis-related expenditure, Rheumatology, 45:92-96, 2006. doi:10.1093/rheumatology/kei114.

21.Velitchkov, A., M. Radoslavova., M. Rasheva, Method about evaluation of generalized expectancies to results (optimism and negative expectancies). Bulgarian journal of psychology, 3: 85-100, 1993

22.Lorig K, Stewart A, Ritter P, González V, Laurent D, \& Lynch J, Outcome Measures for Health Education and other Health Care Interventions. Thousand Oaks CA: Sage Publications, pp. 24-25, 41-45, 1996.

23.Broadbent, Elizabeth, Keith J. Petrie, Jodie Main, John Weinman, The Brief Illness Perception Questionnaire. Journal of Psychosomatic Research, 60: 631-63, 2006.

24.Henselmans Inge, Joke Fleer, Jakob de Vries, Peter C Baas, Robbert Sanderman, Adelita V Ranchor. The adaptive effect of personal control when facing breast cancer: Cognitive and behavioural mediators, Psychology \& Health, 6:89-112, 2009.

25.Mineva K., Petkova M., Nikolov V. Health locus of control and pain tolerance among groups with different socio-cultural characteristics. Trakia Journal of science, 13 (2) 175-179, 2015. 
26.Schiaffino, K. M.\& Revenson, T. A., Relative contributions of spousal support and illness appraisals to depressed mood in arthritis patients. Arthritis Care \& Research, 8: 80- 87, 1995.

27.O'Hea EL, Moon S, Grothe KB, Boudreaux E, Bodenlos JS, Wallston K, Brantley PJ. The interaction of locus of control, selfefficacy, and outcome expectancy in relation to HbA1c in medically underserved individuals with type 2 diabetes. J Behav Med:; 32(1):106-17, 2009.

28.Bekke-Hansen S, Weinman J, Thastum M, Thygesen K, Zachariae R., Psycho-social factors are important for the perception of disease in patients with acute coronary disease. Dan Med J., 61(8):A4885, 2014.

29.Treharne, G.George D Kitas, Antonia C Lyons, David A Booth Well-being in rheumatoid arthritis: the effects of disease duration and psychosocial factors, Journal of Health Psychology, 10 (3): 457-475, 2005.

30.Woby, S., Roach, N., Urmston, M., \& Watson, P., The relation between cognitive factors and levels of pain and disability in chronic low back pain patients presenting for physiotherapy. European Journal of Pain, 11: 869-877, 2007.

31. Nikolov. V., M. Petkova, E. Hristakieva, I.Mantchev, V. Stoqnov, Influence of anxiety on chronic pain perception. Trakia Journal of Science, 6 (2): 39-43, 2008.

32.Petkova, M, Nikolov V. Pain sensitivity among women with low estrogens levels. Procedia-Social and Behavioural Sciences, 5: 289-293, 2010.

33. Seville JL, Robinson AB. Locus of control in the patient with chronic pain. In: Gatchel RJ, Weisberg JN, (Eds). Personality characteristics of patients with pain. American Psychological Association; Washington, DC, US: pp. 165-179, 2000. DOI: $10.1037 / 10376-007$.

34.Tomich, P. L., \& Helgeson, V. S., Is finding something good in the bad old ways good? Benefit finding among women with breast cancer. Health Psychology, 23(1): $16-23$, 2004. doi: 10.1037/02786133.23.1.16

35.Nikolov. V., M. Petkova, Ts. Stanilova. Passive coping style and chronic pain. Bulgarian journal of psychology,1-2: 153162, 2011. 